BMJ Open Sport \& Exercise Medicine

\title{
Cardiorespiratory fitness and physical function in children with cancer from diagnosis throughout treatment
}

Troels Thorsteinsson, ${ }^{1}$ Hanne Baekgaard Larsen, ${ }^{1}$ Kjeld Schmiegelow, ${ }^{1,2}$ Lone Friis Thing, ${ }^{3}$ Peter Krustrup, ${ }^{4,5}$ Mogens Theisen Pedersen, ${ }^{3}$ Karl Bang Christensen, ${ }^{6}$ Pernille Rudebeck Mogensen, ${ }^{1,7}$ Anne Sofie Helms, ${ }^{1}$ Lars Bo Andersen ${ }^{8,9}$

To cite: Thorsteinsson T, Larsen HB, Schmiegelow K, et al. Cardiorespiratory fitness and physical function in children with cancer from diagnosis throughout treatment. BMJ Open Sport Exerc Med 2017;3: e000179. doi:10.1136/bmjsem-2016000179

- Prepublication history and additional material for this paper are available online. To view these files please visit the journal online (http://dx. doi.org/10.1136/bmjsem2016-000179)

Accepted 27 November 2016

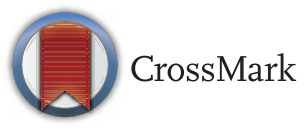

For numbered affiliations see end of article.

Correspondence to Dr Lars Bo Andersen; lars. bo.andersen@hvl.no

\section{ABSTRACT}

Background Children with cancer experience severe reductions in physical fitness and functionality during and following intensive treatment. This may negatively impact their quality of life.

Purpose To describe the physical capacity and functionality of children with cancer during and after treatment as well as the feasibility of physical activity intervention in the Rehabilitation including Social and Physical activity and Education in Children and Teenagers with Cancer study.

Patients and methods The study included children diagnosed from January 2013 to April 2016 with paediatric cancer or Langerhans cell histiocytosis, all treated with chemotherapy. Seventy-five of 78 consecutively eligible children (96.2\%) were included. Median age was 11 years (range 6-18). The physical capacity and function were assessed based on testing of physical strength, balance and cardiorespiratory fitness. Children were tested at diagnosis, 3 and 6 months after diagnosis and 1 year after cessation of treatment. The feasibility evaluation was inspired by the criteria for reporting the development and evaluation of complex interventions in healthcare.

Results All children participated in the physical intervention programme with no dropouts. Strenuous physical exercise and physiological testing during paediatric cancer treatment was safe and feasible, with only five minor adverse events during the intervention. Cardiorespiratory fitness was significantly lower in children with cancer than norms for healthy agematched children at diagnosis (difference $19.1 \mathrm{~mL} / \mathrm{kg}$ / min, $95 \% \mathrm{Cl} 15.4$ to $22.7 ; p<0.0001$ ), during treatment 3 and 6 months from diagnosis (difference $21.0 \mathrm{~mL} / \mathrm{kg} /$ $\min , 95 \% \mathrm{Cl} 17.4$ to $24.6 ; \mathrm{p}<0.0001$ and difference $21.6 \mathrm{~mL} / \mathrm{kg} / \mathrm{min}, 95 \% \mathrm{Cl} 17.3$ to $25.8 ; p<0.0001$, respectively) and 1 year after cessation of treatment (difference $6.9 \mathrm{~mL} / \mathrm{kg} / \mathrm{min}, 95 \% \mathrm{Cl} 1.1$ to 12.7 ; $\mathrm{p}<0.0072)$. Furthermore, children with cancer experienced a pronounced decline in physical function. Conclusion This study shows that it is safe and feasible to perform strenuous physical exercise and testing during paediatric cancer treatment and that children with cancer have significantly lower physical capacity and functionality than healthy age-matched norms.

\section{What are the new findings? \\ - It is feasible to conduct a supervised and individ- ualised physical exercise intervention during paediatric cancer treatment. \\ - Strenuous physical exercise and physiological testing during paediatric cancer treatment is safe. \\ - Cardiorespiratory fitness and function is signifi- cantly lower than norms from age-matched healthy children at diagnosis, during treatment and after treatment.}

How might it impact on clinical practice in the future?

Rehabilitation should start at diagnosis to preserve physical function and healthy habits.

- Physical exercise and activity during anticancer therapy should be promoted.

Trial registration number ClinicalTrials.gov: NCT01772862.

\section{BACKGROUND}

Increased understanding of childhood cancer biology, improved surgical techniques and intensified risk-group-adapted chemotherapy and radiotherapy have led to a 5 -year overall survival rate above $80 \%$ in childhood cancer. $^{1-3}$ However, this improvement comes at a cost. The combination of intensive treatment, severe side effects and isolation regimens, as well as immunosuppression and a treatmentrelated sedentary lifestyle, compromises the activity level of the children. ${ }^{14-6}$ In addition, participation in physical activity with peers is reduced. ${ }^{1}{ }^{7} \quad 8$ This negatively impacts the children's emotional well-being and health-related quality of life. ${ }^{5}{ }^{10}$ Few 
studies have addressed physical activity levels in children with cancer. Most studies have relatively small sample sizes, cover only cancer subsets and describe diverse exercise interventions, outcome measurements and durations. ${ }^{781112}$ Overall, the studies indicate that children with cancer are less physically active and have decreased muscle strength, balance and cardiorespiratory fitness during and even years after cessation of treatment compared with their peers. ${ }^{7}{ }^{11-13}$ A longterm decline in physical fitness can lead to metabolic disease, and previous studies have shown associations between cardiorespiratory fitness and single cardiovascular disease risk factors in childhood. ${ }^{14}{ }^{15}$ However, this can be moderated by physical activity. ${ }^{14} 15$ Of paramount importance is the link between fitness and parameters that influence cancer cells, for example, insulin sensitivity and the immune system. ${ }^{16}{ }^{17}$ Animal studies have indicated that physical activity inhibits cancer cell growth. ${ }^{18}$

It is unknown whether it is possible to implement a safe and feasible physical exercise intervention during the very intensive treatment regimens for childhood cancer and the concomitant decline in physical capacity, strength and function. Participation in physical activity may cause sore muscles and stress injuries. However, there are no reports in the existing literature on such injuries due to physical training in children with cancer. Thus, the level of intensity at which children with cancer can exercise is uncertain.

The aim of this study was to describe physical capacity and functionality in children with cancer during and after treatment as well as the feasibility of physical activity intervention in the RESPECT study (Rehabilitation including Social and Physical activity and Education in Children and Teenagers with Cancer-ClinicalTrials. gov: NCT01772862). ${ }^{19}$

\section{METHODS AND DESIGN Intervention design}

The RESPECT study is an integrated part of Centre for Integrated Rehabilitation of Cancer Patients-a research centre established and supported by the Danish Cancer Society and the Novo Nordisk Foundation aiming to explore how early-intervention strategies, including physical activity, influence rehabilitation of children and adults with cancer. The RESPECT study is a nationwide population-based, prospective, controlled and mixed methods intervention study. The children with cancer were activated and motivated to be physically and socially active during treatment by professional and psychosocial support. The evaluation of feasibility of the intervention is inspired by the criteria for reporting the development and evaluation of complex interventions in healthcare guidelines describing aims, the theoretical background, intervention components, strategy, motivations and barriers, and compliance. ${ }^{20}$

\section{Physical intervention programme and setting}

The intervention programme was conducted by a trained exercise psychology consultant (first author, TT) in the paediatric oncology ward. The in-hospital intervention combined daily participation in supervised individual physical activity and group-based physical activities twice weekly with other children with cancer and healthy classmates (ambassadors). As part of the RESPECT study, the hospitalised children each had two healthy classmates assigned to them as ambassadors. The ambassadors visited the child with cancer at the hospital (9 a.m. to 3 p.m.) at alternating 2-week intervals and participated in the intervention programme. A more detailed description of the physical intervention has been reported previously. ${ }^{19}$ Supplementary file 1 outlines some of the most common exercises used in this intervention. Inclusion criteria for physical training sessions and physiological testing were developed in collaboration with the chief senior physician and professor at the paediatric oncology ward and were haemoglobin above $5 \mathrm{mmoL} / \mathrm{L}$; platelets above 10 billion/L at moderate intense and intense exercise and by testing and above 50 billion/L in 'contact sport'; and consent from patients and parents. Exclusion criteria were temperature equal to or above $38.5^{\circ} \mathrm{C}$; active diarrhoea, coughing, cold; and severe comorbidities that prevented physical activity.

\section{Participants}

From January 2013 to April 2016, 75 of 78 consecutively eligible children (96.2\%) were included in the RESPECT study. The group comprised children undergoing treatment for cancer at Copenhagen University Hospital. Eligibility criteria were: age 6-18 years; diagnosed with cancer, Langerhans cell histiocytosis or myelodysplastic syndrome; treated with chemotherapy; enrolled in school at the time of diagnosis and able to communicate in Danish. Exclusion criteria were limited to mental disability (eg, Down's syndrome) or severe comorbidity. Table 1 shows the demographic and clinical characteristics of the intervention population.

\section{Physical tests}

The intervention programme was quantified using the following physiological tests: $\mathrm{VO}_{2 \text { peak }}$, Timed-Up-andGo, Sit-to-Stand, Grip strength, Flamingo balance and Andersen Fitness test (see detailed description in supplementary file 2). Monitoring took place at diagnosis, 3 and 6 months after diagnosis and 1 year after cessation of treatment. Level of activity prediagnosis was collected at diagnosis (self-reported) and level of participation was registered after each training session.

\section{Statistical analysis}

Measurements of the endpoints $\mathrm{VO}_{2 \text { peak }}$, STS, TUG, Balance and Grip strength taken at four study time points (at diagnosis, 3 and 6 months after diagnosis 
Table 1 Demographic and clinical characteristics of the intervention population

\begin{tabular}{|c|c|}
\hline Variables & $n=75$ \\
\hline \multicolumn{2}{|l|}{ Demographics } \\
\hline Females/males & $29(39 \%) / 46(61 \%)$ \\
\hline Age at diagnosis (median, range) & $\begin{array}{l}11 \text { years } \\
\text { (6-18 years) }\end{array}$ \\
\hline Danish ethnicity/other ethnicity & 66 (88\%)/9 (12\%) \\
\hline \multicolumn{2}{|l|}{ Diagnoses } \\
\hline Acute lymphoblastic leukaemia & $24(32.0 \%)$ \\
\hline Acute myeloid leukaemia & $4(5.3 \%)$ \\
\hline Myelodysplastic syndrome & V1 $(1.3 \%)$ \\
\hline Acute promyelocytic leukaemia & $2(2.8 \%)$ \\
\hline Central nervous system tumour & $8(10.7 \%)$ \\
\hline Lymphoma & $14(18.7 \%)$ \\
\hline Extracranial solid tumour & $21(28.0 \%)$ \\
\hline Langerhans cell histiocytosis & $1(1.3 \%)$ \\
\hline \multicolumn{2}{|l|}{ Location of tumours } \\
\hline Upper limb & 8 \\
\hline Lower limb & 7 \\
\hline Torso (organs and genitals) & 5 \\
\hline Brain & 8 \\
\hline \multicolumn{2}{|l|}{ Treatment } \\
\hline CT & $48(64.0 \%)$ \\
\hline $\mathrm{CT}+\mathrm{S}$ & $15(20.0 \%)$ \\
\hline $\mathrm{CT}+\mathrm{RT}$ & $3(4.0 \%)$ \\
\hline $\mathrm{CT}+\mathrm{RT}+\mathrm{S}$ & $9(12.0 \%)$ \\
\hline Vincristine & $61(81.3 \%)$ \\
\hline Stem cell transplantation & $10(13.3 \%)$ \\
\hline
\end{tabular}

$\mathrm{CT}$, chemotherapy; RT, radiotherapy; S, surgery.

and 1 year after cessation of treatment) are reported as mean and SD or median and IQR, as appropriate. Linear mixed models using a heterogeneous $\mathrm{AR}^{1}$ covariance structure are used for evaluating change over time. The analyses are adjusted for the effect of diagnosis, gender and age, and the baseline measurements are further adjusted for the time from diagnosis to first measurement. Change scores, and their 95\% CIs are estimated from the model parameters using the delta method. Heart rates of children with cancer and healthy classmates are compared using a linear mixed model in a data set with 294 heart rate measurements (163 from children with cancer and 131 from healthy classmates) from a total of 97 children (50 children with cancer and 47 healthy classmates). The age of the 50 children with cancer was median
Table 2 Prediagnosis activity level, level of participation, dropouts, physiological test performed, time from diagnosis to baseline and safety measures as well as ambassador feasibility

$(n=75)$

\begin{tabular}{ll}
\hline Physical activity & \\
\hline Active before diagnosis* & $33.3 \%$ \\
& $(25 / 75)$ \\
\hline Not active before diagnosis* & $66.6 \%$ \\
& $(50 / 75)$ \\
\hline Participation in individual training sessions & $100 \%$ \\
& $(75 / 75)$ \\
\hline Participation in group training sessions & $96 \%$ \\
& $(72 / 75)$ \\
\hline Dropouts during intervention & $0 \%$ \\
\hline Individual sessions per child, mean & $(0 / 75)$ \\
(range) & 37 \\
\hline Group sessions per child, mean (range) & $(8-83)$ \\
\hline Individual training sessions & $(1-23)$ \\
\hline Group training sessions & $>3100$ \\
\hline Number of physiological tests & $>300$ \\
\hline Time from diagnosis to baseline test, & 758 \\
\hline median (IQR) & $(4.5-19.0)$ \\
\hline Safety & \\
\hline Adverse events during training sessions & 5 \\
\hline
\end{tabular}

*Active defined as $60 \mathrm{~min}$ of moderate to vigorously activity three times per week. ${ }^{34}$

$\dagger$ Adverse events were four minor bruises during training sessions and one incident of a few seconds of fainting after a $\mathrm{VO}_{2 \text { peak }}$ test.

age 11 years (range 6-16) and $39.1 \%$ were girls. Comparisons with a normal population were made using an age- and gender-matched subsample from the reference data sets with five controls sampled for each child with cancer. The cardiorespiratory fitness norm values $(\mathrm{mL} / \mathrm{kg} / \mathrm{min})$ for healthy children used for comparison were collected from Denmark, Norway, Estonia and Portugal. ${ }^{21-25}$ For each time point differences between the children with cancer and the matched controls were compared using a Wilcoxon test. From these cohorts, data for each age group between 6 and 18 years were separated and mean values calculated. These were adjusted for cohort 
Table 3 Number of physiological tests conducted at different time points

\begin{tabular}{lllll}
\hline & $\begin{array}{l}\text { At } \\
\text { diagnosis } \\
(\mathbf{n}=\mathbf{7 5})\end{array}$ & $\begin{array}{l}\text { Three months after } \\
\text { diagnosis } \\
(\mathbf{n}=68)\end{array}$ & $\begin{array}{l}\text { Six months after } \\
\text { diagnosis } \\
(\mathbf{n}=67)\end{array}$ & $\begin{array}{l}\text { One year after cessation of } \\
\text { treatment } \\
(\mathbf{n}=16)\end{array}$ \\
\hline $\begin{array}{l}\text { VO } 2 \text { peak } \\
\text { Sit-to-stand }\end{array}$ & $58(25.3 \%)$ & $19(27.4 \%)$ & $19(28.4 \%)$ & $13(81.3 \%)$ \\
\hline $\begin{array}{l}\text { Timed Up-and- } \\
\text { Go }\end{array}$ & $54(72.0 \%)$ & $48(70.6 \%)$ & $45(67.2 \%)$ & $14(87.5 \%)$ \\
\hline Balance & $64(85.3 \%)$ & $52(76.5 \%)$ & $44(65.7 \%)$ & $15(93.8 \%)$ \\
\hline Grip strength & $68(90.7 \%)$ & $55(80.9 \%)$ & $46(68.7 \%)$ & $15(93.8 \%)$ \\
\hline
\end{tabular}

effects and the protocol used (treadmill or cycle test). ${ }^{26}$ p Values below 0.05 (two-sided) were considered statistically significant.

\section{RESULTS}

Table 2 shows prediagnosis activity level, level of participation in the physical activity intervention, dropouts during the intervention, number of physiological test performed and time from diagnosis to baseline tests, safety measures as well as ambassador feasibility.

Table 3 shows the number of physiological tests conducted at different time points. The RESPECT study is an ongoing study, which explains the different numbers at different time points.

Table 4 shows the different reasons for non-compliance to the $\mathrm{VO}_{2 \text { peak }}$ test (1) medical restrictions, (2) not capable, (3) not motivated, (4) treatment compliance, (5) measurement error and (6) late inclusion.

Intensity during physiological testing and training sessions remained generally high. Table 5 shows the relative intensity of the group training sessions monitored by heart rate over a period of 2 years from 1 September 2013 to 1 September 2015. Children with cancer had a higher average heart rate during training sessions than their healthy peers. Table 5 also presents maximal heart rate and respiratory exchange ratio (RER) during $\mathrm{VO}_{2 \text { peak }}$ testing.

\section{Physiological test results}

Table 6 shows the statistics of the $\mathrm{VO}_{2 \text { peak }}$ at the different time points, at diagnosis, at 3 and 6 months and 1 year after cessation of treatment, compared with a healthy age- and gender-matched control. Children with cancer had significantly lower $\mathrm{VO}_{2 \text { peak }}(\mathrm{mL} / \mathrm{kg} /$ min) than age- and gender-matched controls sampled from population reference data at every time point.

The difference in numbers in tables 4 and 6 is due to the exclusion of brain and bone tumours and stem cell transplantation (SCT). We excluded this group from the comparative analysis.

Table 7 shows the statistics and development of the physiological testing in children with cancer at diagnosis, 3 and 6 months postbaseline and 1 year after cessation of treatment. The analyses are adjusted for the effect of diagnosis, gender and age, and the baseline measurements are further adjusted for the time from diagnosis to first measurement. Change scores and their 95\% CIs are estimated.

Figure 1A-F shows the statistics and development of the physiological testing in children with cancer at diagnosis, 3 and 6 months postbaseline and 1 year after cessation of treatment. The connecting lines indicate the average development in physical performance during treatment.

Table 4 Reasons for non-compliance to $\mathrm{VO}_{2 \text { peak }}$ test

\begin{tabular}{|c|c|c|c|c|c|c|c|c|}
\hline \multirow[b]{2}{*}{ Reasons } & \multicolumn{2}{|c|}{ Baseline } & \multicolumn{2}{|c|}{ Three months } & \multicolumn{2}{|c|}{ Six months } & \multicolumn{2}{|c|}{ Cessation after 12 months } \\
\hline & $\mathbf{n}$ & $\%$ & $\mathbf{n}$ & $\%$ & $\mathbf{n}$ & $\%$ & $\mathbf{n}$ & $\%$ \\
\hline 1 & 16 & 28.6 & 12 & 23.5 & 16 & 33.3 & 1 & 33.3 \\
\hline 2 & 28 & 50.0 & 30 & 58.8 & 24 & 50.0 & 2 & 66.7 \\
\hline 3 & 3 & 5.4 & 4 & 7.8 & 4 & 8.3 & - & - \\
\hline 4 & 3 & 5.4 & 3 & 5.9 & 4 & 8.3 & - & - \\
\hline 5 & 3 & 5.4 & - & - & - & - & - & - \\
\hline 6 & 3 & 5.4 & 2 & 3.9 & - & - & - & - \\
\hline Total & 56 & - & 49 & - & 48 & - & 3 & - \\
\hline
\end{tabular}


Table 5 Relative intensity monitored by heart rate and respiratory exchange ratio (RER)

During group training sessions

\begin{tabular}{|c|c|c|c|c|c|}
\hline Variable & Group & Mean & \multicolumn{2}{|c|}{$95 \% \mathrm{Cl}$} & $\mathrm{p}$ Value \\
\hline \multirow[t]{2}{*}{$\mathrm{HR}_{\text {average }}$ (beats/min) } & Children with cancer $(n=50)$ & 145.3 & 141.7 & 148.9 & $<0.0001$ \\
\hline & Ambassador $(n=47)$ & 127.8 & 123.5 & 131.1 & \\
\hline \multirow[t]{2}{*}{$\mathrm{HR}_{\max }(\mathrm{bpm})$} & Children with cancer $(n=50)$ & 185.2 & 180.8 & 189.5 & 0.0556 \\
\hline & Ambassador $(n=47)$ & 178.9 & 174.3 & 183.6 & \\
\hline \multicolumn{6}{|l|}{ During $\mathrm{VO}_{2 \text { peak }}$ test } \\
\hline Variable & Group & $\mathrm{HR}_{\max }($ median, bpm) & \multicolumn{3}{|c|}{ RER (median) } \\
\hline $\mathrm{VO}_{2 \text { peak }}$ test & Children with cancer & 192 & \multicolumn{2}{|l|}{1.23} & \\
\hline
\end{tabular}

\section{DISCUSSION}

This study shows that it is safe and feasible to perform strenuous physical exercise and comprehensive physiological testing during treatment for paediatric cancer. Cardiorespiratory fitness is significantly lower than norms from age-matched healthy children at diagnosis, during treatment and even 1 year after cessation of treatment. A pronounced decline in physical capacity, muscle strength and physical function is present throughout the entire course of treatment and even small improvements could be considered vital and be the difference between living a normal everyday life and a life in constant dependency on others.

The RESPECT study is based on experiences from an unpublished pilot study, a theoretical framework, and earlier intervention studies of children with cancer. Reliable evidence on successful rehabilitation in children with cancer is lacking and we believe that
RESPECT will contribute with novel relevant knowledge about treatment and rehabilitation of children with cancer and is probably also applicable to other children hospitalised with long-term illness.

\section{Feasibility and safety}

All 75 children included in the RESPECT study took part in the physical activity sessions (table 2). Three children had no hospital admissions, but only a few outpatient visits and did not take part in group training sessions (table 2). Frequency and compliance mainly differed depending on diagnosis, inpatient days and level of side effects. There were no dropouts from the intervention programme (table 2). Thus, every child taking part in the intervention attended and completed the physical exercise sessions until either cessation of treatment or death.

\begin{tabular}{|c|c|c|c|c|c|c|c|c|c|}
\hline & Group & $\mathbf{n}$ & Median & $\begin{array}{l}\text { 25th } \\
\text { percentile }\end{array}$ & $\begin{array}{l}\text { 75th } \\
\text { percentile }\end{array}$ & p Value & Mean & SD & $\begin{array}{l}\text { Difference of } \\
\text { means }\end{array}$ \\
\hline \multirow[t]{2}{*}{ Diagnosis } & RESPECT & 17 & 30.4 & 24.7 & 34.1 & $<0.0001$ & 29.8 & 5.7 & $\begin{array}{l}19.1 \text { (15.4 to } \\
22.7)\end{array}$ \\
\hline & $\begin{array}{l}\text { Matched } \\
\text { controls }\end{array}$ & 85 & 49.7 & 43.7 & 54.6 & & 48.9 & 7.1 & \\
\hline \multirow[t]{2}{*}{3 months } & RESPECT & 19 & 27.7 & 23.9 & 29.7 & $<0.0001$ & 27.3 & 6.3 & $\begin{array}{l}21.0(17.4 \text { to } \\
24.6)\end{array}$ \\
\hline & $\begin{array}{l}\text { Matched } \\
\text { controls }\end{array}$ & 95 & 49.5 & 42.0 & 54.5 & & 48.4 & 7.4 & \\
\hline \multirow[t]{2}{*}{6 months } & RESPECT & 16 & 23.6 & 20.0 & 36.1 & $<0.0001$ & 27.7 & 10.2 & $\begin{array}{l}21.6(17.3 \text { to } \\
25.8)\end{array}$ \\
\hline & $\begin{array}{l}\text { Matched } \\
\text { controls }\end{array}$ & 80 & 49.9 & 43.8 & 54.8 & & 49.2 & 7.3 & \\
\hline \multirow[t]{2}{*}{ Cess. +12 months } & RESPECT & 8 & 39.4 & 38.2 & 43.8 & 0.0072 & 40.6 & 4.7 & 6.9 (1.1 to 12.7$)$ \\
\hline & $\begin{array}{l}\text { Matched } \\
\text { controls }\end{array}$ & 40 & 48.4 & 41.5 & 54.3 & & 47.5 & 7.8 & \\
\hline
\end{tabular}


Table 7 Shows the statistics and development of the physiological testing in children with cancer at diagnosis, 3 and 6 months postbaseline and 1 year after cessation of treatment

\begin{tabular}{|c|c|c|c|c|c|c|c|}
\hline \multirow{2}{*}{$\begin{array}{l}\text { Variables } \\
\mathrm{VO}_{2 \text { peak }}(\mathrm{mL} / \mathrm{kg} / \mathrm{min})\end{array}$} & \multirow{2}{*}{$\begin{array}{l}\text { Time } \\
\text { Diagnosis }\end{array}$} & \multirow{2}{*}{$\begin{array}{l}\text { Mean } \\
32.1\end{array}$} & \multicolumn{2}{|c|}{$95 \% \mathrm{Cl}$} & \multirow{2}{*}{$\begin{array}{l}\text { Change from } \\
\text { diagnosis }\end{array}$} & \multicolumn{2}{|l|}{$95 \% \mathrm{Cl}$} \\
\hline & & & 27.5 & 36.7 & & & \\
\hline & 3 months & 25.8 & 22.9 & 28.7 & -6.3 & -10.8 & -1.8 \\
\hline & 6 months & 27.5 & 23.3 & 31.7 & -4.6 & -9.9 & 0.8 \\
\hline & Cess. +12 months & 37.6 & 34.0 & 41.2 & 5.5 & 0.3 & 10.7 \\
\hline \multirow[t]{4}{*}{$\mathrm{VO}_{2 \text { peak }}(\mathrm{L} / \mathrm{min})$} & Diagnosis & 1.4 & 1.1 & 1.6 & - & & \\
\hline & 3 months & 1.2 & 1.0 & 1.4 & -0.2 & -0.4 & 0.1 \\
\hline & 6 months & 1.4 & 1.1 & 1.7 & 0.0 & -0.3 & 0.3 \\
\hline & Cess. +12 months & 1.9 & 1.6 & 2.2 & 0.5 & V0.2 & 0.8 \\
\hline \multirow[t]{4}{*}{ STS (repetitions) } & Diagnosis & 28.0 & 25.2 & 30.9 & - & & \\
\hline & 3 months & 22.7 & 20.2 & 25.2 & -5.4 & -8.2 & -2.5 \\
\hline & 6 months & 23.9 & 21.1 & 26.7 & -4.1 & -7.6 & -0.7 \\
\hline & Cess. +12 months & 29.5 & 26.3 & 32.7 & 1.5 & -2.3 & 5.2 \\
\hline \multirow[t]{4}{*}{ Timed-up-and-Go (time) } & Diagnosis & 3.7 & 3.4 & 4 & - & & \\
\hline & 3 months & 4.5 & 4.2 & 4.8 & 0.8 & 0.4 & 1.2 \\
\hline & 6 months & 4.5 & 4.1 & 4.8 & 0.8 & 0.3 & 1.2 \\
\hline & Cess. +12 months & 3.5 & 3.2 & 3.7 & -0.2 & -0.6 & 0.2 \\
\hline \multirow[t]{4}{*}{ Grip strength left hand } & Diagnosis & 19.7 & 17.6 & 21.8 & - & & \\
\hline & 3 months & 17.3 & 15.3 & 19.3 & -2.4 & -4.2 & -0.5 \\
\hline & 6 months & 18.0 & 15.9 & 20.1 & -1.7 & -4.0 & 0.5 \\
\hline & Cess. +12 months & 23.6 & 21.0 & 26.3 & V3.9 & 1.1 & 6.8 \\
\hline \multirow[t]{4}{*}{ Grip strength right hand } & Diagnosis & 21.5 & 19.1 & 23.8 & - & & \\
\hline & 3 months & 19.0 & 17.0 & 20.9 & -2.5 & -4.5 & -0.4 \\
\hline & 6 months & 20.7 & 18.4 & 23.1 & -0.8 & -3.3 & 1.8 \\
\hline & Cess. +12 months & 25.9 & 23.4 & 28.5 & 4.5 & 1.5 & 7.4 \\
\hline
\end{tabular}

We registered only five adverse events (table 2). This is a low number of incidents and determines our precautions, inclusion criteria and physical exercise and testing as appropriate.

Fifteen of 75 children had restrictions in relation to physiological testing based on a medical assessment (table 2). These cases related primarily to brain and bone tumours and SCT. We excluded this group from the comparative analysis (table 6).

From August 2012 to January 2013, we conducted an unpublished pilot study to test whether the components of the main study were feasible. The pilot study focused on the processes of the main study, safety measures, intervention scheme and physiological assessments. The pilot study indicated that we would be able to allocate two suitable ambassadors to more than $95 \%$ of patients, and that they will be able to cope with the challenges linked to their participation. Subsequently, during the intervention study, we have seen that it is possible to allocate ambassadors for all children and that the ambassadors were highly motivated for providing inhospital patient support during childhood cancer therapy (table 2). ${ }^{27} 28$

\section{Physical exercise and testing}

Due to the wide heterogeneity of the group (table 1), child-specific interests, individual aims and motivations to be physically active (Thorsteinsson $\mathrm{T}$, Schmiegelow $\mathrm{K}$, Andersen LB, et al. Classmates motivate childhood cancer patients to participate in physical activity during treatment: a qualitative study. European Journal of Cancer Care, submitted.), designing a safe and acceptable intervention with a high level of compliance requires tailoring. Furthermore, the physical ability of children with cancer fluctuates considerably and can change rapidly from day-to-day and even from hour-tohour. To meet this challenge, the daily exercise sessions 
were tailored to each child's needs, age, gender, side effects, capabilities, fitness level, level of activity prediagnosis and support from their social network. Social and mental skills training were performed when the child with cancer was not able to perform physical exercise as well as during exercise sessions and social sessions. Supplementary file 1 outlines the exercises primarily used in the physical training programme. The focus was on stability/balance, mobility, strength (resistance) and cardiorespiratory fitness. Several of the exercises affect more than one focus area. The feasibility of the test battery improved as we identified various challenges. The TUG, Flamingo balance, STS and Grip strength tests were easily implemented and could be carried out at the ward in the patient's room in approximately $10 \mathrm{~min}$ and compliance was acceptable (table 3). The $\mathrm{VO}_{2 \text { peak }}$ test needed flexible access to test equipment, which were not available at the beginning of the study. Moreover, the window of opportunity to test children with cancer is very small due to their fluctuating wellbeing, low blood counts and need for medical procedures. Consequently, we purchased our own portable equipment, which led to an increase in the number of $\mathrm{VO}_{2 p e a k}$ tests performed due to greater flexibility and access. As expected, compliance was low in the number of $\mathrm{VO}_{2 \text { peak }}$ tests performed in contrast to the other test,

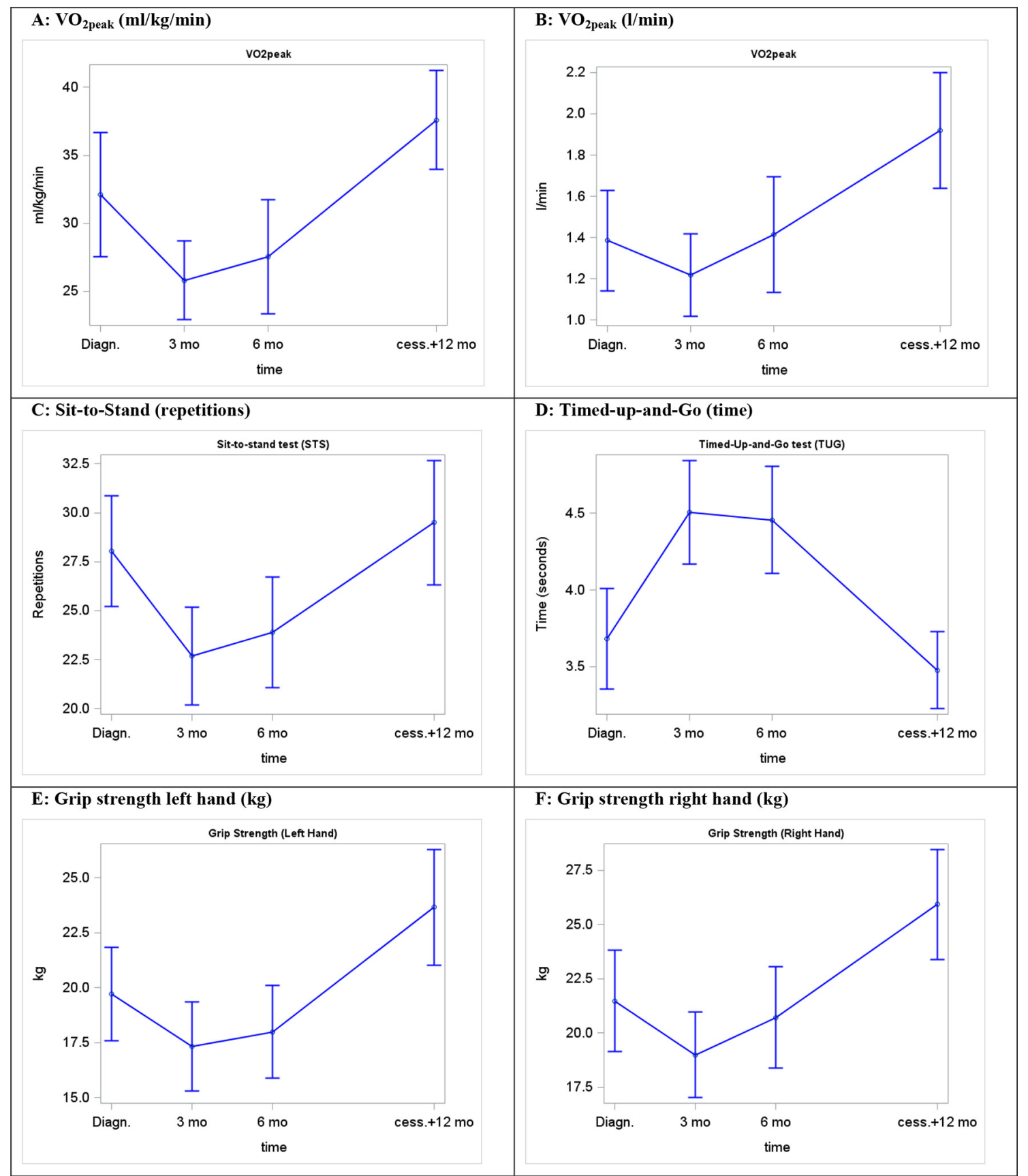

Figure 1 (A) $\mathrm{VO}_{2 \text { peak }}(\mathrm{mL} / \mathrm{kg} / \mathrm{min}),(\mathrm{B})$ : $\mathrm{VO}_{2 \text { peak }}(\mathrm{L} / \mathrm{min})$, (C) Sit-to-Stand (repetitions, $\left.\mathrm{n}\right)$, (D) Timed-up-and-Go (time, s) and (E,F) Grip strength $(\mathrm{kg})$. 
and there seems to be an association between the number of tests performed and the length and intensity of the test (table 3). Furthermore, it seems like the decline in physical capacity and strength and consequently reduced physical function during treatment affects the completion rate of physical tests (table 3). The reasons for not performing the test were mainly severe treatment side effects, medical procedures or medical restrictions (table 4). Reasons for better compliance in TUG, Flamingo balance, STS and Grip strength tests were primarily the reduced length and intensity of the test, easier to complete despite pain and discomfort, fewer restrictions and physically and mentally less demanding. Future interventions should possibly also include a submaximal $\mathrm{VO}_{2}$ test to enhance the number of tests performed, even though we believe the current $\mathrm{VO}_{2 \text { peak }}$ test shows novel and interesting results.

We excluded the modified flamingo balance test in this study, because the results varied widely. We also excluded the modified Andersen test from the test battery, as we learnt it was not compatible in children with cancer and could not produce a fitness rating similar to the $\mathrm{VO}_{2 \text { peak }}$ test, probably because of our small modification as well as the test has not been validated in a group with such low performance scores.

\section{Intensity during physical exercise sessions}

During group training sessions, we monitored the children's heart rate and found it to be very high even during low-intensity exercise (table 5). Children with cancer had a higher average heart rate during training sessions than their peers. Whether this is due to increased metabolism (increased cell division), poor fitness, physical and/or mental stress, severe illness, low blood counts or severe treatment is unknown. We believe it is mainly due to the poor fitness, but this should be investigated further. This implicates that children with cancer may have severe challenges during everyday activities, such as walking and running and other movements which are typical for children and require aerobe capacity.

\section{Physical capacity and functionality}

The comprehensive monitoring shows that cardiorespiratory fitness is already significantly lower in children with cancer at diagnosis when compared with healthy children (table 6). Physiological test results at diagnosis correlate well with the results from Ness $e t a l^{29}$ and are a strong advocate for early rehabilitation. Starting rehabilitation at diagnosis is pivotal to preserve physical function and prediagnosis habits. The pronounced decline in physical capacity, muscle strength and physical function is present throughout the entire course of treatment (table 7, figure 1A-F). Even at a moderate level of exercise (eg, short walks and other low-intensity activities at moderate pace), heart rate quickly rose above 170 $\mathrm{bpm}$. As a consequence, children with cancer were often only capable of doing exercise or everyday activity in very short intervals, even though the absolute workload normally would be considered low-tomoderate. Accordingly, due to decreased physical fitness of these children, simple everyday activities should be considered so strenuous that they are equivalent to moderate to intense physical training. An earlier study showed that regular everyday physical exercise, such as cycling to school, constitutes physical activity that has positive effects even in healthy children. ${ }^{30}$ As mentioned earlier, reducing the daily activity level is associated with negative metabolic consequences. A study by Olsen et $a l^{31}$ assessed metabolic changes when reducing daily steps and found that young healthy men developed metabolic changes indicative of decreased insulin sensitivity, attenuation of postprandial lipid metabolism and physical changes suggesting that calories used to maintain muscle mass with greater stepping may have been partitioned to visceral fat. As a result, if children with cancer are capable of maintaining an as normal as possible activity level, this actually constitutes moderate- to high-intensity physical activity and may be beneficial for a range of health outcomes.

We have presented cardiorespiratory fitness as a general fitness level and as absolute oxygen uptake because the weight component is essential. Children with cancer often experience a big weight gain during treatment. ${ }^{32}$ Some children with cancer are able to maintain or improve their level of $\mathrm{VO}_{2 \text { peak }}(\mathrm{L} / \mathrm{min})$ from diagnosis to 3 and 6 months after diagnosis, with only their weight is altering. To validate the $\mathrm{VO}_{2 \text { peak }}$ test, we looked at median heart rate and RER. We observed that the median heart rate was $192 \mathrm{bpm}$ and that the median RER was 1.23 , which shows the same development in heart rate during testing as in healthy children; accordingly we have high validity of the $\mathrm{VO}_{2}$ peak testing (table 5).

As shown in table 7 and figure 1, muscle strength and physical function were declined at diagnosis (table 7 , figure $1 \mathrm{C}-\mathrm{F}$ ), which is in agreement with the results from Ness et $a l^{29}$ A highly sedentary lifestyle and everyday life with a serious illness and associated side effects cause a further drastic decline in muscle strength, physical function and balance. STS, balance and TUG performance indicate whether or not a person is fit to move around without any restrictions or special needs and participate in normal everyday activities (eg, climbing stairs, moving from one place to another) whether at home or at school. Grip strength measurement by dynamometry is well standardised, and grip strength correlates with a number of important life functions (eg, self-care, carrying bags, doing homework, opening doors and bottles, etc). ${ }^{33}$ To our knowledge there are no norms in healthy children in the STS and TUG test. 


\section{PERSPECTIVES AND CONCLUSION}

This study shows that it is safe and feasible to perform strenuous physical exercise and testing during paediatric cancer treatment and that children with cancer have a significantly lower cardiorespiratory fitness than healthy age-matched norms even 1 year after cessation of treatment. A pronounced decline in muscle strength and physical function is present throughout treatment. These results reveal that there is a need to re-think rehabilitation in children diagnosed and treated for cancer. Comprehensive professional and psychosocial support, enhancing social and physical activity is a new and highly recommended way forward. The present results can be transferred to a different or similar context and setting relating to rehabilitation of children hospitalised with and burdened by long-term illnesses.

\section{Author affiliations}

${ }^{1}$ Department of Paediatrics and Adolescent Medicine, Copenhagen University Hospital Rigshospitalet, Copenhagen, Denmark

${ }^{2}$ Faculty of Health and Medical Sciences, University of Copenhagen,

Copenhagen, Denmark

${ }^{3}$ Department of Nutrition, Exercise and Sports, University of Copenhagen, Copenhagen, Denmark

${ }^{4}$ Department of Sport and Health Sciences, University of Exeter, College of Life and Environmental Sciences, Exeter, UK

${ }^{5}$ Department of Sports Science and Clinical Biomechanics, SDU Sport and Health Sciences Cluster (SHSC), University of Southern Denmark, Odense, Denmark

${ }^{6}$ Department of Biostatistics, University of Copenhagen, Copenhagen, Denmark

${ }^{7}$ Department of Diabetes and Metabolism, Copenhagen University Hospital Rigshospitalet, Copenhagen, Denmark

${ }^{8}$ Department of Sports Medicine, Norwegian School of Sport Sciences, Oslo, Norway

${ }^{9}$ Department of Teacher Education and Sport, Western Norway University of Applied Sciences, Røyrgata, Norway

Acknowledgements The study was supported by grants from the Novo Nordisk Foundation, the Danish Cancer Society, the Tryg Foundation, the Danish Children's Cancer Foundation, the Hede Nielsen Foundation, the Aase and Ejnar Danielsen Foundation, the Arvid Nielsen Foundation, the Toyota Foundation, the ML Jørgensen and Gunnar Hansen Foundation and the Lundbeck Foundation. The authors would like to thank all of the children and families who participated in this study.

Contributors TT drafted the first version of the manuscript and, together with LBA, was responsible for the physical activity intervention. TT and LFT were responsible for the social activity intervention and ASH was responsible for the educational intervention in the RESPECT study. KS was scientific director and HBL was the main project coordinator for the RESPECT project. PK, MTP and PRM, together with TT and LBA, helped to validate and analyse the results. $\mathrm{KBC}$, together with $\mathrm{TT}$, was responsible for the statistics. All the authors read and approved the final manuscript and completed the ICMJE uniform disclosure form.

Competing interests None declared.

Ethics approval Information on the subjects is protected under the Processing of Personal Data and Health Act. The Danish Data Protection Agency (file. 2007-58-0015/nr.30-0734) and the Regional Ethics Committee for the Capital Region (file. H 3-2012-105) approved the project, and the project complies with the Helsinki II Declaration. In addition, the study is registered at ClinicalTrials.gov (NCT01772849 and NCT01772862). The written informed consent of the relevant parents, guardians and children (above 15 years) was obtained following the provision of oral and written information.

Provenance and peer review Not commissioned; externally peer reviewed.
Open Access This is an Open Access article distributed in accordance with the Creative Commons Attribution Non Commercial (CC BY-NC 4.0) license, which permits others to distribute, remix, adapt, build upon this work noncommercially, and license their derivative works on different terms, provided the original work is properly cited and the use is non-commercial. See: http:// creativecommons.org/licenses/by-nc/4.0/

(C) Article author(s) (or their employer(s) unless otherwise stated in the text of the article) 2017. All rights reserved. No commercial use is permitted unless otherwise expressly granted.

\section{REFERENCES}

1. Brown PD, Olsen $\mathrm{JH}$, Hertz $\mathrm{H}$, et al. Survival after childhood cancer in Denmark 1943-1987. A population-based study. Ugeskr Laeger 1996;158:773-8.

2. Gatta G, Zigon G, Capocaccia R, et al. Survival of European children and young adults with cancer diagnosed 1995-2002. Eur J Cancer 2009;45:992-1005

3. Smith MA, Seibel NL, Altekruse SF, et al. Outcomes for children and adolescents with cancer: challenges for the twenty-first century. J Clin Oncol 2010;28:2625-34.

4. Oeffinger KC, Mertens AC, Sklar CA, et al. Chronic health conditions in adult survivors of childhood cancer. $N$ Engl J Med 2006;355:1572-82.

5. Gurney JG, Krull KR, Kadan-Lottick N, et al. Social outcomes in the childhood cancer survivor study cohort. J Clin Oncol 2009;27:2390-5

6. Stam H, Grootenhuis MA, Last BF. The course of life of survivors of childhood cancer. Psychooncology 2005;14:227-38.

7. Braam KI, van der Torre $\mathrm{P}$, Takken $\mathrm{T}$, et al. Physical exercise training interventions for children and young adults during and after treatment for childhood cancer. Cochrane Database Syst Rev 2016;31:CD008796.

8. Huang TT, Ness KK. Exercise interventions in children with cancer: a review. Int J Pediatr 2011;2011:461512.

9. Mitby PA, Robison LL, Whitton JA, et al. Utilization of special education services and educational attainment among long-term survivors of childhood cancer: a report from the childhood cancer survivor study. Cancer 2003;97:1115-26.

10. DuHamel KN, Redd WH, Vickberg SM. Behavioral interventions in the diagnosis, treatment and rehabilitation of children with cancer. Acta Oncol 1999;38:719-34.

11. Winter C, Müller C, Hoffmann $C$, et al. Physical activity and childhood cancer. Pediatr Blood Cancer 2010;54:501-10.

12. Grimshaw SL, Taylor NF, Shields N. The feasibility of physical activity interventions during the intense treatment phase for children and adolescents with cancer: a systematic review. Pediatr Blood Cancer 2016;63:1586-93.

13. Murnane A, Gough K, Thompson K, et al. Adolescents and young adult cancer survivors: exercise habits, quality of life and physical activity preferences. Support Care Cancer 2015;23:501-10.

14. Jones LW, Liu Q, Armstrong GT, et al. Exercise and risk of major cardiovascular events in adult survivors of childhood hodgkin lymphoma: a report from the childhood cancer survivor study. J Clin Oncol 2014;32:3643-50.

15. Anderssen SA, Cooper AR, Riddoch C, et al. Low cardiorespiratory fitness is a strong predictor for clustering of cardiovascular disease risk factors in children independent of country, age and sex. Eur J Cardiovasc Prev Rehab 2007;14:526-31.

16. McTiernan A. Mechanisms linking physical activity with cancer. Nat Rev Cancer 2008;8:205-11.

17. Pedersen L, Christensen JF, Hojman P. Effects of exercise on tumor physiology and metabolism. Cancer J 2015;21:111-6.

18. Pedersen L, Idorn $\mathrm{M}$, Olofsson $\mathrm{GH}$, et al. Voluntary running suppresses tumor growth through epinephrine- and IL-6-dependent NK cell mobilization and redistribution. Cell Metab 2016;23:554-62.

19. Thorsteinsson T, Helms AS, Adamsen L, et al. Study protocol: Rehabilitation including Social and Physical activity and Education in Children and Teenagers with Cancer (RESPECT). BMC Cancer 2013;13:544

20. Möhler R, Bartoszek G, Köpke S, et al. Proposed criteria for reporting the development and evaluation of complex interventions in healthcare (CReDECI): guideline development. Int J Nurs Stud 2012;49:40-6.

21. Andersen LB, Harro M, Sardinha LB, et al. Physical activity and clustered cardiovascular risk in children: a cross-sectional study (The European Youth Heart Study). Lancet 2006;368:299-304.

22. Andersen LB, Bugge A, Dencker M, et al. The association between physical activity, physical fitness and development of metabolic disorders. Int J Pediatr Obes 2011;6:29-34. 
23. Bugge A, El-Naaman B, Dencker M, et al. Effects of a three-year intervention: the Copenhagen School Child Intervention Study. Med Sci Sports Exerc 2012;44:1310-7.

24. Klasson-Heggebø L, Andersen LB, Wennlöf AH, et al. Graded associations between cardiorespiratory fitness, fatness, and blood pressure in children and adolescents. Br J Sports Med 2006;40:25-9.

25. Steene-Johannessen J, Kolle E, Anderssen SA, et al. Cardiovascular disease risk factors in a population-based sample of Norwegian children and adolescents. Scand J Clin Lab Invest 2009;69:380-6.

26. Mamen A, Resaland GK, Da M, et al. Comparison of peak oxygen uptake in boys exercising on thredmill and cycle ergometers. Gazz. Med.Ital 2008;167:15-21.

27. Baekgaard $\mathrm{H}$, Helms AS, Thorsteinsson $\mathrm{T}$, et al. Feasibility of classmates as ambassadors for children with cancer as facilitators of social-, physical- and educational rehabilitation activities in the RESPECT study.

28. Lindgren LH, Schmiegelow K, Helms AS, et al. In sickness and in health: classmates are highly motivated to provide in-hospital support during childhood cancer therapy. Psychooncology 2017;26:37-43.

29. Ness KK, Kaste SC, Zhu L, et al. Skeletal, neuromuscular and fitness impairments among children with newly diagnosed acute lymphoblastic leukemia. Leuk Lymphoma 2015;56:1004-11.

30. Ostergaard L, Børrestad LA, Tarp J, et al. Bicycling to school improves the cardiometabolic risk factor profile: a randomised controlled trial. BMJ Open 2012;2:e001307.

31. Olsen RH, Krogh-Madsen R, Thomsen C, et al. Metabolic responses to reduced daily steps in healthy nonexercising men. JAMA 2008;299:1261-3.

32. Arpe ML, Rørvig S, Kok K, et al. The association between glucocorticoid therapy and BMI z-score changes in children with acute lymphoblastic leukemia. Support Care Cancer 2015;23:3573-80.

33. Mathiowetz V, Wiemer DM, Federman SM. Grip and pinch strength: norms for 6- to 19-year-olds. Am J Occup Ther 1986;40:705-11.

34. World Health Organisation (WHO). Global recommendations on physical activity for health 2010: Internet Communication. 